\title{
Control and Filter Design of Three-Phase Inverters for High Power Quality Grid Connection
}

\author{
Milan Prodanović, Student Member, IEEE, and Timothy C. Green, Member, IEEE
}

\begin{abstract}
The trend toward using inverters in distributed generation systems and micro-grids has raised the importance of achieving low-distortion, high-quality power export from inverters. Both switching frequency effects and pre-existing grid voltage distortion can contribute to poor power quality. A well designed filter can attenuate switching frequency components but has an impact on the control bandwidth and the impedance presented to grid distortion. This paper describes a filter designed to incorporate an isolating transformer and the design of a complementary controller that rejects grid disturbance, maintains good waveform quality and achieves real and reactive power control. A realistic discrete time implementation is discussed and validated with experimental results.
\end{abstract}

Index Terms-Current estimator, digital control, grid-connection, power quality, three-phase inverter.

\section{INTRODUCTION}

$\mathbf{I}$ N RECENT years, the number of different power resources connected to power systems (voltage grids) has increased and there has been a move toward connecting small power resources to the medium and low voltage networks rather than large resources to the high voltage network. Power sources such as wind turbines and combined heat and power plants (CHP) are already well established and fuel-cells and microturbines are being demonstrated. Many of these resources use synchronous generators for the interconnection to the grid. However, there has been an increase in the number of sources that are natural dc sources or whose ac frequency is either not constant or is much higher than the grid frequency. In some of these cases three-phase inverters have been used. So far, only small-scale power applications have used inverters because of limited component availability, heat dissipation problems, reliability concerns and cost.

High-power semiconductor switches with reasonable switching frequency have become more available and it is expected that there will be more inverter applications in small-scale power generation (up to $1 \mathrm{MVA}$ ). The trend toward modular construction of power electronic systems can increase power capacity and also improve system efficiency.

Power quality standards for connection of an inverter to the grid are still under development, since previously there have been few similar high power applications. In [1] it is stated that the power quality is determined by the voltage quality, when

Manuscript received February 1, 2002; revised September 5, 2002. Recommended by Associate Editor S. B. Leeb.

The authors are with the Department of Electrical and Electronic Engineering, Imperial College, London SW7 2BT, UK (e-mail: proca@ic.ac.uk; t.green@ic.ac.uk).

Digital Object Identifier 10.1109/TPEL.2002.807166 the voltage is a controlled variable. If there is connection to an existing (stiff) grid, then the voltage cannot be controlled. The power quality is then defined by the current quality. Further, it is specified [2] that the inverter must not oppose or regulate the voltage at the point of common coupling (PCC). Another important aspect of power quality is harmonic distortion. General requirements for harmonic distortion can be found in standard [3] and particularly for connection of distributed resources to the grid in [3].

Most distributed resources are connected to the grid via an isolating transformer. Power supply companies demand this for the elimination of possible zero sequence or dc components in the generated voltages and for the increased protection it affords. This fact can be used as an advantage since the transformer can form part of a filter impedance and may, therefore, reduce the undesired harmonic content of the output current.

During the past decade, digital control in power electronics has been intensively used. Microprocessor and DSP speeds have increased allowing improved flexibility, reliability and complexity of control algorithms. A number of papers, such as [4], [5], have appeared dealing with the properties and limitations of digital control.

This paper proposes a control solution that provides high quality of current injected into a voltage grid and, therefore, high power quality. In addition, active and reactive power control is provided. Because of the importance of attenuating switching frequency components, filter design is discussed and the added filter components are taken into account during the control design. The choice of control variables and control strategy is discussed and an appropriate control topology proposed. The implementation of the digital control combines phase-lock, current control and power control loops. Theoretical analysis and experimental results are provided to demonstrate the validity of the proposed method.

\section{CONNECTION OF AN INVERTER TO THE GRID}

A standard inverter interface to the grid is shown in Fig. 1, where $L$ represents either a discrete inductor or the winding inductance of an isolating transformer. A pulse-width modulation scheme would ensure that the inverter voltage $v_{I}$ is free from low-order harmonic distortion. However, high frequency current emissions due to the switching frequency must be attenuated and pre-existing grid voltage distortion should not be allowed to drive harmonic currents through the inverter.

An improved inverter connection to the grid is shown in its per-phase form in Fig. 2. Four major sub-systems can be recognized in this diagram: the inverter bridge, inverter output filter, 
isolating transformer and the grid. In this arrangement, the harmonic content of the injected current can be better controlled, and therefore the power quality can be improved. The switching frequency components can not be suppressed by the control, but can be minimized during the design process as discussed later. Harmonic distortion in the output current originating from the grid voltage can be rejected by a careful choice of control strategy and this will be examined in the Section IV. It is, therefore, important to determine the impedance presented by the isolating transformer so that it can be used as a parameter during both the filter design and the controller design.

The grid voltage $v_{G}$ at the point of common coupling (PCC) is not always available to sense and the assumption that will be used here is that only the local inverter variables can be sensed, namely the inductor currents $i_{L}$, capacitor voltages $v_{O}$ and output currents $i_{O}$.

\section{Filter Design CONSIDERATIONS}

Before describing the controller design, certain aspects of the inverter design must be addressed so that they complement the controller.

\section{A. Impact of an Isolating Transformer}

Isolating transformers are normally designed under the assumption that only fundamental frequency $(50$ or $60 \mathrm{~Hz}$ ) voltages and currents are applied. These components are of interest for power control, but from the power quality point of view it is important to investigate transformer characteristics across a wide frequency range. The methods presented in [6] and [7] are used to estimate model parameters and the characteristics of the transformer at higher harmonics.

A typical per phase equivalent circuit of an isolating transformer for the low frequency range $(<20 \mathrm{kHz})$ is shown in Fig. 3. It is assumed that the secondary side components are moved to the primary side and that the transformer is designed for similar (referred) winding impedances on both sides. The winding resistance and copper losses are represented by the series resistance $R_{S}$ and the series inductance $L_{S}$ represents the inductive effect of the leakage flux. $L_{M}$ models mutual inductance of the windings, and $R_{M}$ models the power losses in the magnetic core.

It was demonstrated in [6] and [7] that most parameters do not change significantly within the frequency range of interest. The most significant change [6] is that of series resistance $R_{S}$, but it is desirable to assume the lowest possible resistance, which represents the worst case scenario for filter design.

The equivalent impedance $Z_{T}$ of the transformer (1) is calculated looking from the inverter side toward the grid. The impedance seen by the inverter is usually larger than this because of the grid impedance, but this calculation provides the minimum impedance that can be expected. Impedances $Z_{S}$ and $Z_{M}$ represent equivalent series and magnetizing impedances and are given in

$$
\begin{aligned}
& Z_{T}=Z_{S}+Z_{S} \| Z_{M} \stackrel{\left|Z_{S}\right| \ll\left|Z_{M}\right|}{=} 2 Z_{S} \\
& Z_{S}=R_{S}+s L_{S}, \quad Z_{M}=R_{M} \| s L_{M} .
\end{aligned}
$$

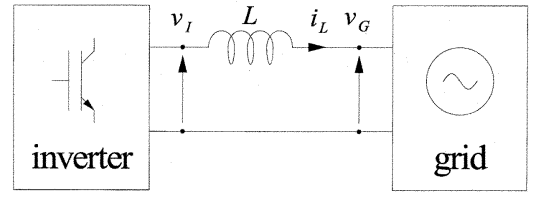

Fig. 1. Inverter connected to a voltage grid.

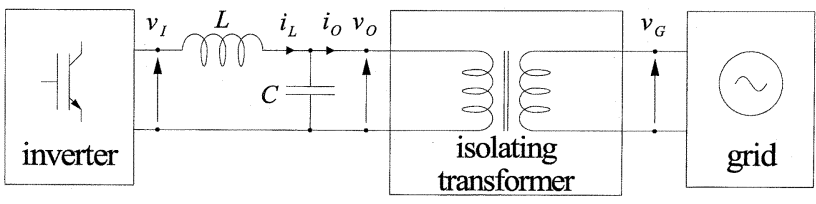

Fig. 2. Inverter connected to a voltage grid via a 2 nd order filter and an isolating transformer.

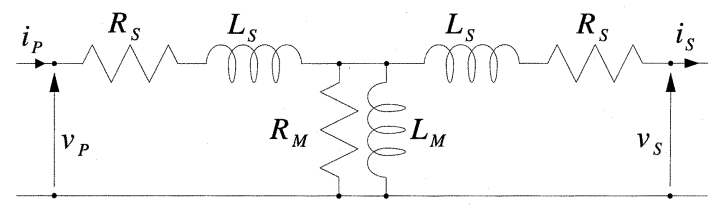

Fig. 3. Equivalent circuit of an isolating transformer.

\section{B. Choice of Inverter Filter Components}

The output $L C$ filter is there to filter out undesired switching frequency components from the output current spectrum. The switching frequency used in high power applications is chosen with regard to the inefficiency of the converter due to switching losses. It is desirable, from the point of view of size and cost of filtering components, to increase the switching frequency, but the converter efficiency sets the limit and a design trade-off must be made. For the filter design, it is assumed that the switching frequency $f_{S}$ has been determined and is fixed.

The inductor value $L$ is chosen to limit the inductor current ripple. If the lowest value of the inductance is chosen, the size and cost of the component can be reduced. The procedure how to calculate the inductor value for a specified current ripple is explained in [8]. There is also an advantage in a three-phase three-wire inverter under balanced conditions that some harmonics in the current spectrum do not appear because they are zero-sequence components. This reduces the inductance required. Around the switching frequency there are two dominant components in the inductor current spectrum which are given in Equation (3), where $f_{O}$ is the fundamental frequency and $V_{O}$ nominal voltage. Further harmonic analysis is given in [9]

$$
I_{L}\left(f_{S} \pm 2 f_{O}\right)=\frac{V_{O}\left(f_{O}\right)}{4 L 2 \pi\left(f_{S} \pm 2 f_{O}\right)} .
$$

Before connection to the grid is made, the switching frequency spectral components of inductor current have to be filtered out according to the requirements stated in [2] and [3]. The filtering has to be done using a shunt impedance which has a low magnitude at the switching frequency. On the other hand, this impedance should have a high magnitude within control frequency range in order to minimize the impact of grid voltage harmonics on the output current. A natural choice for this impedance is a capacitance. The capacitor value should be 
kept as small as reasonable to minimize the current flow due to low-order harmonics while still providing the necessary low impedance path for high frequency distortion.

Parameters of the isolating transformer can be used to obtain the minimum value required for the filter capacitor. The choice for capacitor impedance can be made from inequality (4). In this formula $Z_{C}$ and $Z_{T}$ represent the capacitor and equivalent transformer impedances, assuming the secondary is connected to an ideal voltage source. $I_{N O M}$ is the nominal output current at line frequency $(50$ or $60 \mathrm{~Hz})$ and $p$ the desired attenuation of harmonic content compared to the nominal current at the switching frequency $f_{S}$

$$
\left|\frac{Z_{C}\left(f_{S}-2 f_{O}\right)}{Z_{C}\left(f_{S}-2 f_{O}\right)+Z_{T}\left(f_{S}-2 f_{O}\right)}\right|<\frac{p I_{N O M}}{\mid I_{L}\left(f_{S}-2 f_{O}\right)} .
$$

Filter components chosen in the way described here will provide sufficient attenuation of switching frequency components in the output current spectrum.

\section{CONTROL STRATEGY}

In many examples of grid connection of an inverter [10], [11] the inverter is operated as a voltage source where the inverter voltage applied to the filter ( $v_{I}$ in Figs. 1 and 2$)$ is controlled. By mimicking the operation of a synchronous generator (through manipulating the phase and magnitude of the voltage) the output active and reactive powers have been successfully controlled. Because in this mode the inverter generates an ideal sinusoidal pulse-width modulated signal at its output, the output current and power quality depend on the grid voltage quality. Only when the grid voltage quality is high can the current and power quality also be high. If the grid voltage is distorted or if there is voltage imbalance in the grid, the exported output current is distorted or unbalanced. This relation degrades the output power quality, since the generating system adds to the distortion of the grid by presenting a low impedance to existing distortion voltage. An equivalent circuit diagram for a voltage controlled inverter is shown in Fig. 4.

Another approach is to operate the inverter as a current source where the inductor current $i_{L}$ is controlled. This approach improves power quality because the output current quality is influenced less by the grid voltage quality. The main advantage of using a current source instead of a voltage source is that within the control frequency range a higher output impedance is observed from the point of view of the grid voltage. This minimizes the effect of voltage harmonics on the output current and improves the power quality. The idea is to operate the inverter such that it can be represented as in Norton's theorem with a current source and impedance in parallel shown in Fig. 5.

Current-mode control has been chosen for this work because of its ability to reject existing grid voltage distortion. The control strategy is to control the inverter to generate high quality balanced three-phase currents and to control power at the output of the inverter. If this is achieved, the inverter does not represent a harmonic source connected to the grid, but instead appears as a high quality power generator.

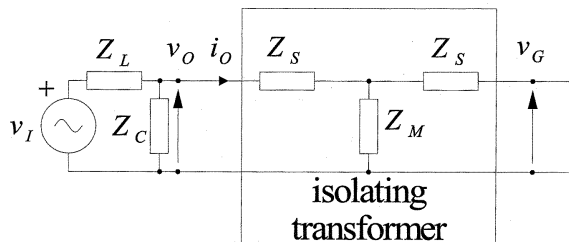

Fig. 4. Per-phase equivalent circuit for an inverter mimicking a synchronous machine.

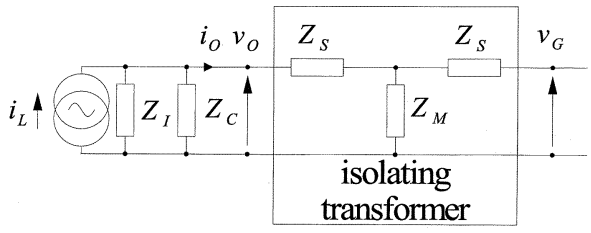

Fig. 5. Per-phase equivalent circuit for an inverter under current-mode control.

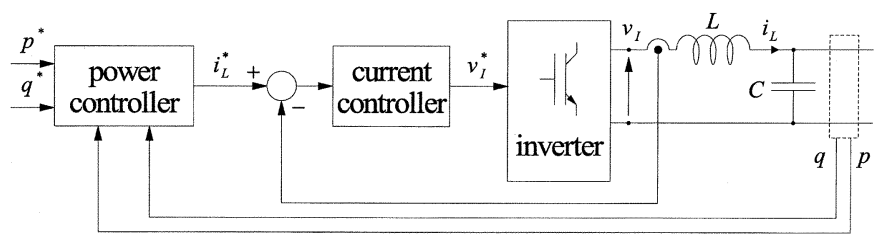

Fig. 6. Simplified form of the real and reactive power control loops.

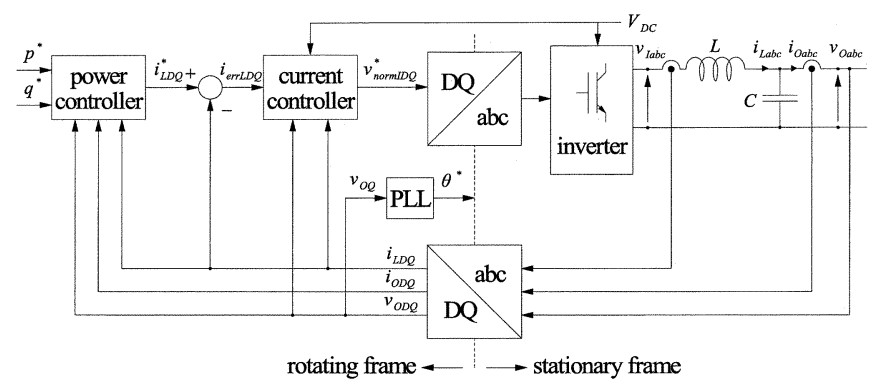

Fig. 7. Control topology for grid connection of an inverter.

\section{CONTROL TOPOLOGY}

A simplified control topology for grid connection of an inverter is shown in Fig. 6. In this arrangement, the power controller calculates the inductor current reference $i_{L}^{*}$ so as to achieve the output power reference and a local current control loop maintains the inductor current value.

A full control topology for grid connection of a threephase inverter is shown in Fig. 7. Several decoupling terms and a current predictor are present in addition to the simple feedback loops of Fig. 6. The current control is performed in a rotational reference frame because of the effectiveness of PI controllers operating on the pseudo-stationary voltages and currents. However, there have been recent attempts [12] and [13] to perform the control in the stationary frame. The accurate control of fundamental frequency currents has been achieved, but at the expense of complex filtering circuit and limited bandwidth of control. Instantaneous active and reactive power can be readily calculated in the rotating reference frame [14]. A third control loop, a phase-locked loop, is added to provide the reference angle for the rotating frame. 


\section{A. Phase-Locked Loop}

There are two basic approaches to the realization of a phase-locked loop (PLL) for a three-phase voltage system. One [15] uses a method of error minimization between a square wave signal derived from the input voltage by a zerocrossing comparator and the signal from the local oscillator. The alternative method [16]-[18] uses the rotational reference frame to obtain the $D$ and $Q$ components of three-phase voltages. In this method, when one of those components is controlled to be constant then the frequency of the $D Q$-system has been set to the frequency of grid voltage. It is convenient to arrange the regulator to maintain one component at zero by changing the frequency of rotation of the $D Q$-system. In the case of a distorted or unbalanced system, this approach is more suitable because it accurately locks to the frequency of fundamental despite the distortion.

\section{B. Current Control}

An inductor current control loop is essential for obtaining high power quality in grid connection of inverters. It provides three-phase balanced current injection to the grid. Another advantage of using current control is that nonlinearities, such as inverter switching and external disturbances, are dealt with within that loop. There are two sources of disturbance to the current control: changes in the dc-link voltage $V_{d c}$ and disturbance of the grid voltage.

The current control is performed in the rotational reference frame. The system equations are shown in (5), where $\omega$ is the grid angular frequency, $L$ the inductance and $v_{I}$ inverter voltage. The filter output voltage $v_{O}$ represents a disturbance to the current control loop

$$
\begin{aligned}
{\left[\begin{array}{c}
\dot{i_{L D}} \\
\dot{i_{L Q}}
\end{array}\right]=} & {\left[\begin{array}{rr}
0 & \omega \\
-\omega & 0
\end{array}\right]\left[\begin{array}{l}
i_{L D} \\
i_{L Q}
\end{array}\right] } \\
& +\frac{1}{L}\left[\begin{array}{ll}
1 & 0 \\
0 & 1
\end{array}\right]\left[\begin{array}{l}
v_{I D} \\
v_{I Q}
\end{array}\right]-\frac{1}{L}\left[\begin{array}{ll}
1 & 0 \\
0 & 1
\end{array}\right]\left[\begin{array}{l}
v_{O D} \\
v_{O Q}
\end{array}\right]
\end{aligned}
$$

When the system is discretized [4], further coupling terms appear between the axes. The system equations are now shown in (6) and (7) for a sampling period of $T$ and a switching period equal to the sample period

$$
\begin{gathered}
{\left[\begin{array}{c}
i_{L D}(k+1) \\
i_{L Q}(k+1)
\end{array}\right]=A\left[\begin{array}{c}
i_{L D}(k) \\
i_{L Q}(k)
\end{array}\right]+B\left[\begin{array}{l}
v_{I D}(k) \\
v_{I Q}(k)
\end{array}\right]-F\left[\begin{array}{l}
v_{O D}(k) \\
v_{O Q}(k)
\end{array}\right]} \\
A=\left[\begin{array}{cc}
\cos (\omega T) & \sin (\omega T) \\
-\sin (\omega T) & \cos (\omega T)
\end{array}\right] \\
B=F=\frac{1}{\omega L}\left[\begin{array}{cc}
\sin (\omega T) & 1-\cos (\omega T) \\
-1+\cos (\omega T) & \sin (\omega T)
\end{array}\right] .
\end{gathered}
$$

Equation (8) is used to provide decoupling between axes, where $v_{C D}(k)$ and $v_{C Q}(k)$ are the controller outputs and $\widehat{i}_{L D}(k)$ and $\widehat{i}_{L Q}(k)$ are estimated current values at $k T$. The estimation has to be made since the computational delay of one sampling time must be taken into account. There are standard

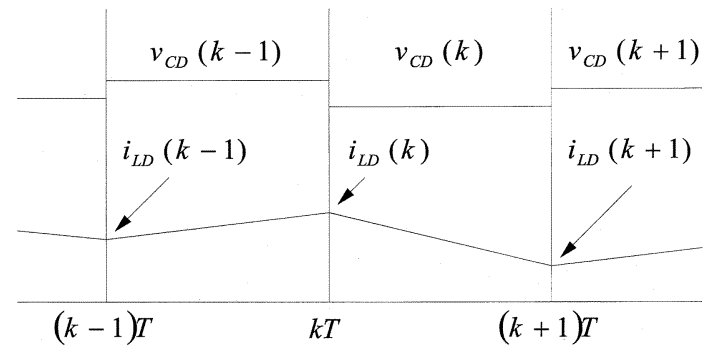

Fig. 8. Sampling.

techniques available to overcome this problem by inserting an estimator to minimize the effect of the delay time [5]

$$
\begin{aligned}
{\left[\begin{array}{l}
v_{I D}(k) \\
v_{I Q}(k)
\end{array}\right] } & =\frac{\sin (\omega T)}{\omega L} B^{-1} \\
& \cdot\left(\left[\begin{array}{cc}
0 & -\omega L \\
\omega L & 0
\end{array}\right]\left[\begin{array}{c}
\hat{i}_{L D}(k) \\
\hat{i}_{L Q}(k)
\end{array}\right]+\left[\begin{array}{l}
v_{C D}(k) \\
v_{C Q}(k)
\end{array}\right]\right)
\end{aligned}
$$

As shown in Fig. 8, the sampled values at the time $(k-1) T$ are used to calculate the output voltage vector during the time interval up to $k T$. Instead of controlling the sampled current value of $i_{L D}(k-1)$, the estimated value $\widetilde{i_{L D}}(k)$ will be used. In this way the phase-margin of the control system can be improved and, therefore, the bandwidth of the loop gain increased.

The estimator equation is given in (9) where the matrix $G$ is the estimator gain

$$
\begin{aligned}
{\left[\begin{array}{c}
\hat{i}_{L D}(k) \\
\hat{i}_{L Q}(k)
\end{array}\right]=} & \cos (\omega T)\left[\begin{array}{c}
\hat{i}_{L D}(k-1) \\
\hat{i}_{L Q}(k-1)
\end{array}\right] \\
& +\frac{\sin (\omega T)}{\omega L}\left[\begin{array}{c}
v_{C D}(k-1) \\
v_{C Q}(k-1)
\end{array}\right]-F\left[\begin{array}{c}
v_{O D}(k-1) \\
v_{O Q}(k-1)
\end{array}\right] \\
& +G\left[\begin{array}{c}
i_{L D}(k-1)-\widehat{i}_{L D}(k-1) \\
i_{L Q}(k-1)-\widehat{i}_{L Q}(k-1)
\end{array}\right]
\end{aligned}
$$

The poles of the two decoupled estimator loops are given in (10). The estimator gains are selected as in (11) to provide dead-beat control

$$
\begin{aligned}
z & =\cos (\omega T)-g \\
G & =\left[\begin{array}{cc}
\cos (\omega T) & 0 \\
0 & \cos (\omega T)
\end{array}\right] .
\end{aligned}
$$

Now, the estimator equations can be reduced and the estimated values of currents can be obtained from

$$
\begin{aligned}
& {\left[\begin{array}{l}
\hat{i}_{L D}(k) \\
\hat{i}_{L Q}(k)
\end{array}\right]=\cos (\omega T)\left[\begin{array}{l}
i_{L D}(k-1) \\
i_{L Q}(k-1)
\end{array}\right]} \\
& \quad+\frac{\sin (\omega T)}{\omega L}\left[\begin{array}{l}
v_{C D}(k-1) \\
v_{C Q}(k-1)
\end{array}\right]-F\left[\begin{array}{l}
v_{O D}(k-1) \\
v_{O Q}(k-1)
\end{array}\right] .
\end{aligned}
$$

The structure of the current controller used within Fig. 7 is shown in Fig. 9. The low frequency disturbance coming from variation of the dc-bus voltage is compensated by normalizing the controller output vectors.

The $D$-axis current controller within Fig. 9 is shown in more detail in Fig. 10. A PI controller is used to obtain zero steadystate error and compensate for inverter switching nonlinearities 


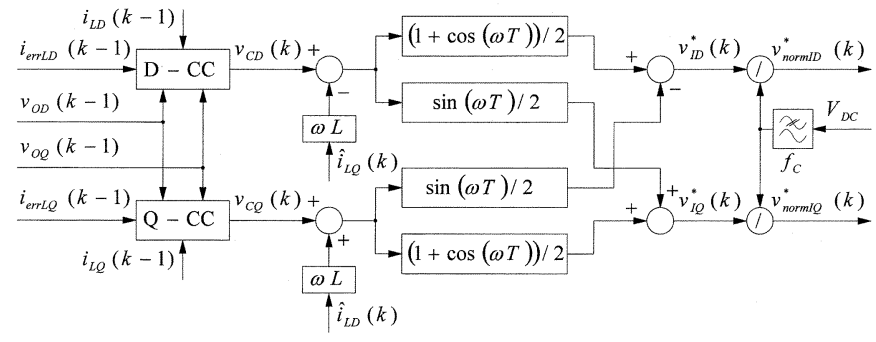

Fig. 9. Current controller structure used within Fig. 7 including decoupling terms.

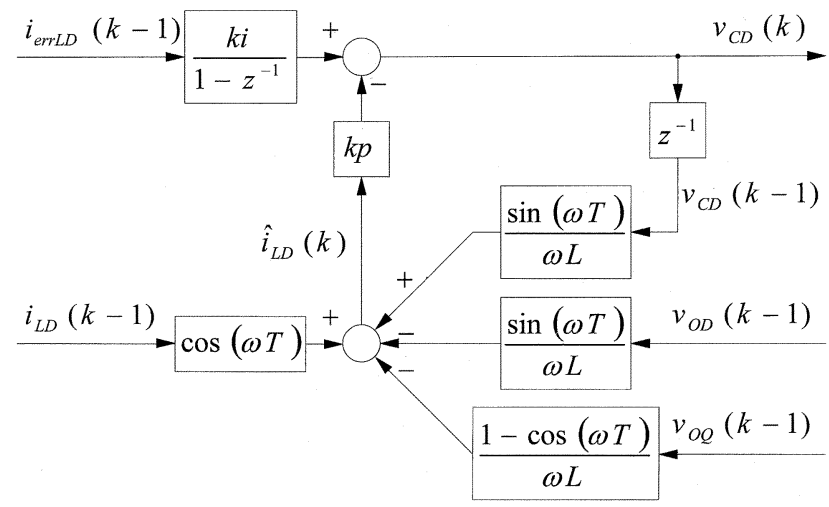

Fig. 10. $D$-axis current controller structure incorporating the estimator terms.

and inductor nonidealities. The proportional gain is introduced in the feed-back branch and it controls the loop bandwidth and stabilizes the system. The integral term is applied to the error signal and it provides zero steady-state error. The calculation of the estimated value of $\widehat{i_{L D}}(k)$ according to (12) can also be seen in the diagram.

\section{Power Control}

There are two methods to control power: instantaneous and average power control. In the instantaneous power control method, the fundamental current component and higher frequency components are controlled to compensate for the grid voltage disturbances in a similar way to the operation of active power filters. A consequence of regulating the instantaneous power is that if the grid voltage is distorted then the current will necessarily be nonsinusoidal in order to keep the power instantaneously constant. If the objective is to provide high power quality then instantaneous power control should not be used.

The average power control method provides high quality sinusoidal output current and controls the average power flow. The role of the power controller is to generate output current references by filtering out higher harmonic content from the power spectrum. Since the power control transient response time is of the order of $100 \mathrm{~ms}$, the filtering provides a slowly changing current reference to ensure high quality inductor current. A consequence of average power control is that if the grid voltage is distorted then the instantaneous power fluctuates. The fluctuations are reflected to the dc side as harmonic frequencies that are sourced from the dc-link capacitor.

If current control is established and the current $D$ and $Q$ components are kept constant, then the output power variation de-

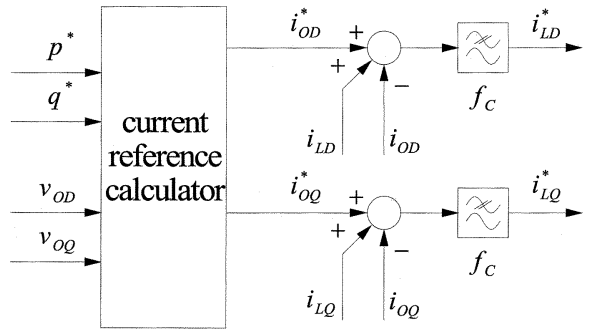

Fig. 11. Power controller structure.

pends only on the variation of output voltages. When the power references $p^{*}$ and $q^{*}$ and output voltages are known, a power calculator can be used (instead of a power controller) to calculate output current references $i_{O D}$ and $i_{O Q}$. The references are calculated according to

$$
\left[\begin{array}{c}
i_{O D}^{*} \\
i_{O D}^{*}
\end{array}\right]=\left[\begin{array}{rr}
v_{O D} & v_{O Q} \\
-v_{O Q} & v_{O D}
\end{array}\right]^{-1}\left[\begin{array}{c}
p^{*} \\
q^{*}
\end{array}\right]
$$

To calculate inductor current references $i_{L D}^{*}$ and $i_{L Q}^{*}$ the capacitor currents and decoupling terms must be added to the output current references. Therefore, the difference between the inductor currents $i_{L D}\left(i_{L Q}\right)$ and output currents $i_{O D}\left(i_{O Q}\right)$ is added to the output current reference $i_{O D}^{*}\left(i_{O Q}^{*}\right)$. The power controller structure is shown in Fig. 11. To limit the power controller bandwidth and to filter out harmonic content from the voltage and current spectrum a low-pass filter is applied. The filter cut-off frequency $f_{C}$ must be set low to provide sufficient suppression of voltage harmonics and unbalance, but high enough to provide good response of the power control loop.

\section{EXPERIMENTAL RESULTS}

An experimental rig was built with an inverter of $10 \mathrm{kVA}$ connected to a $50 \mathrm{~Hz}$ voltage grid via an $\Delta-Y 10 \mathrm{kVA}$ isolating transformer (with a primary to secondary voltage ratio of 415/208 Vrms line-to-line). The inverter parameters are: $f_{S}=$ $8.192 \mathrm{kHz}$, current loop bandwidth $1.9 \mathrm{kHz}, R M S$ voltage loop bandwidth $50 \mathrm{~Hz}, C=50 \mu \mathrm{F}, L=1.35 \mathrm{mH}$. The isolating transformer parameters are: $R_{S}=20 \mathrm{~m} \Omega, L_{S}=100 \mu \mathrm{H}$, $R_{M}=1 \mathrm{k} \Omega, L_{M}=100 \mathrm{mH}$.

A design constraint was that the switching frequency components in the output current should be attenuated $60 \mathrm{~dB}$ below the nominal current value at the $50 \mathrm{~Hz}$. The inductor value was chosen to provide $36 \mathrm{~dB}$ attenuation according to (3) and, therefore, the filter capacitor had to provide more than $24 \mathrm{~dB}$ to satisfy the overall requirement. At the frequency of $f_{S}-2 f_{O}$ it was calculated from (4) that the minimum capacitance value should be $28 \mu \mathrm{F}$. Therefore, a value of $50 \mu \mathrm{F}$, which will insert an attenuation of $28 \mathrm{~dB}$, was chosen.

Full digital control was applied. A TMS320LF2407 DSP was used to implement the control algorithms and to generate PWM signals to drive the inverter.

The measured grid voltage $v_{G}$, inductor current $i_{L}$ and output current $i_{O}$ are shown in Fig. 12 under nominal active power. The grid voltage shows a phase-shift of $30^{\circ}$ (and had higher RMS value), because it represents line-to-line voltage whereas $v_{O}$ was measured as a phase voltage. 


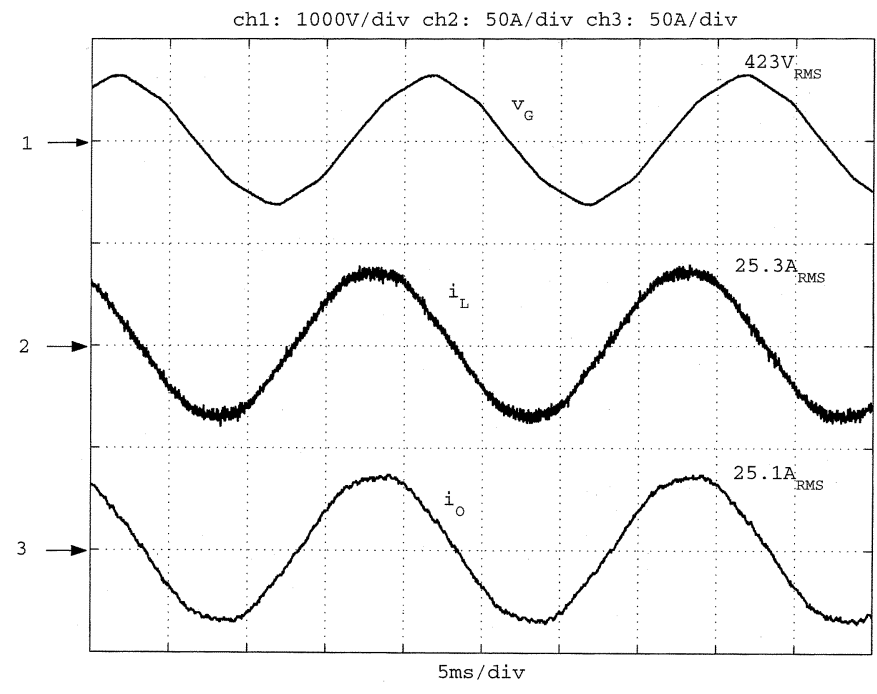

Fig. 12. Grid line voltage, inductor current and output current under nominal output power.

To observe the attenuation of the switching frequency components, the inductor and output current are shown across wider frequency range in Figs. 13 and 14. It can be seen that switching frequency components of the inductor current are attenuated to more than $37 \mathrm{~dB}$ below the fundamental frequency component. For the output current the attenuation is $63 \mathrm{~dB}$, which meets the requirement set.

The grid voltage spectrum is shown in the controlled frequency range in Fig. 15. It can be seen that significant fifth and seventh harmonics already exist. The inductor and output current spectra are shown in Figs. 16 and 17. Calculated THD values show the high quality of both the inductor current (2\%) and the output current $(2.8 \%)$ with the grid voltage quality of $2.8 \%$. The distribution of harmonics in the output current spectrum shows attenuation of 5th and 7th harmonic, but also shows the effect of high bandwidth of the current control resulting in more noise introduced at higher frequencies. It can be seen that the output current quality is lower than the inductor current quality because of the effect of grid voltage distortion.

The characteristics of the power control loop are shown in Fig. 18. The instantaneous active and reactive power references and controller responses are shown in this diagram. The change in the active power reference was from $20 \%$ to $80 \%$, while for the reactive power it was from $0 \%$ to $40 \%$ (capacitive) of nominal inverter power. It can be seen that the power output of the inverter follows its reference and that average power control has been established.

The inverter output impedance was measured by setting active and reactive power references to zero. Phase voltage and current were measured and the output impedance $Z_{O}$ calculated across the frequency range of interest. The result is shown in Fig. 19 and is compared to the impedance of the output capacitor. For an ideal current source the output impedance would be equal to the capacitor impedance. Since the power controller controls the fundamental frequency component, the impedance at that frequency is high. At other frequencies, the output impedance follows the capacitor impedance, but it is smaller due to finite output impedance of the inverter.

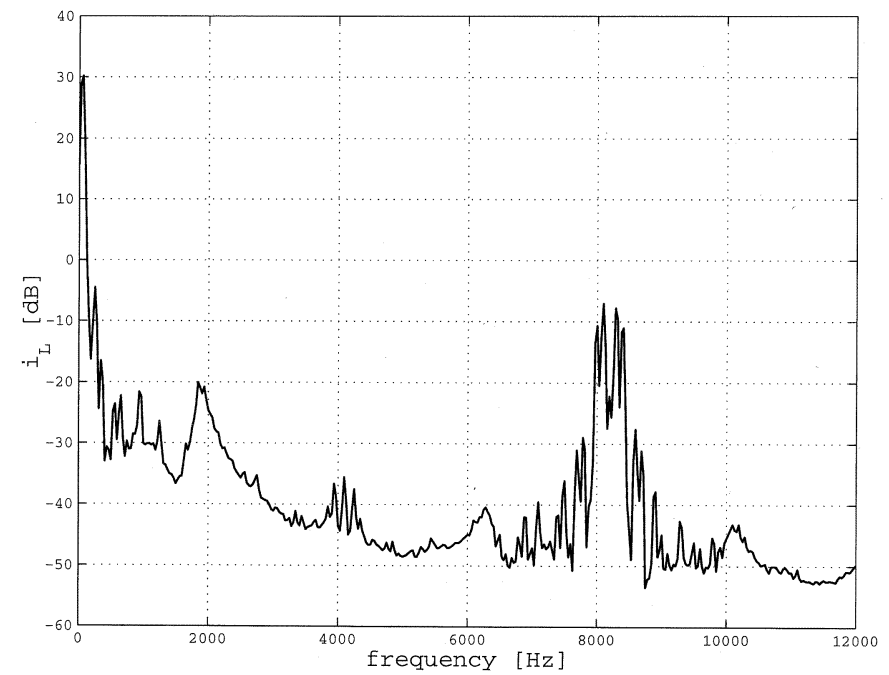

Fig. 13. Inductor current spectrum showing switching frequency components.



Fig. 14. Output current spectrum showing switching frequency components.

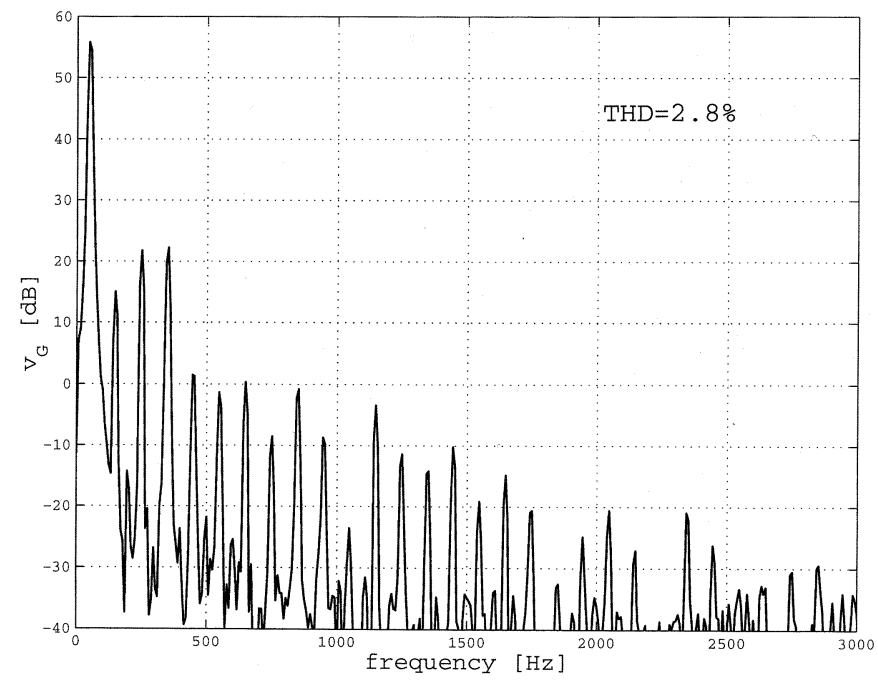

Fig. 15. Line voltage spectrum. 


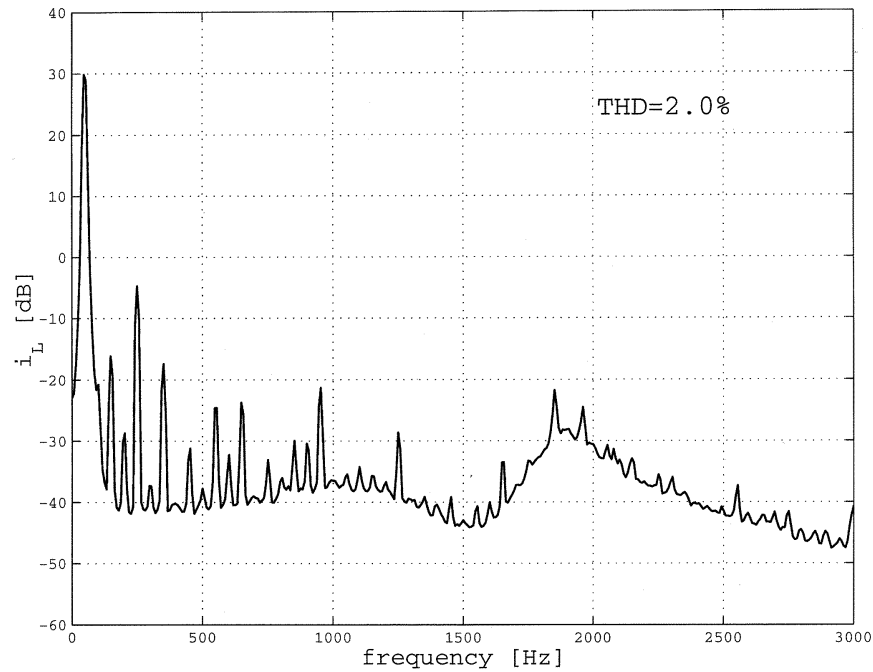

Fig. 16. Inductor current spectrum in controlled frequency range.

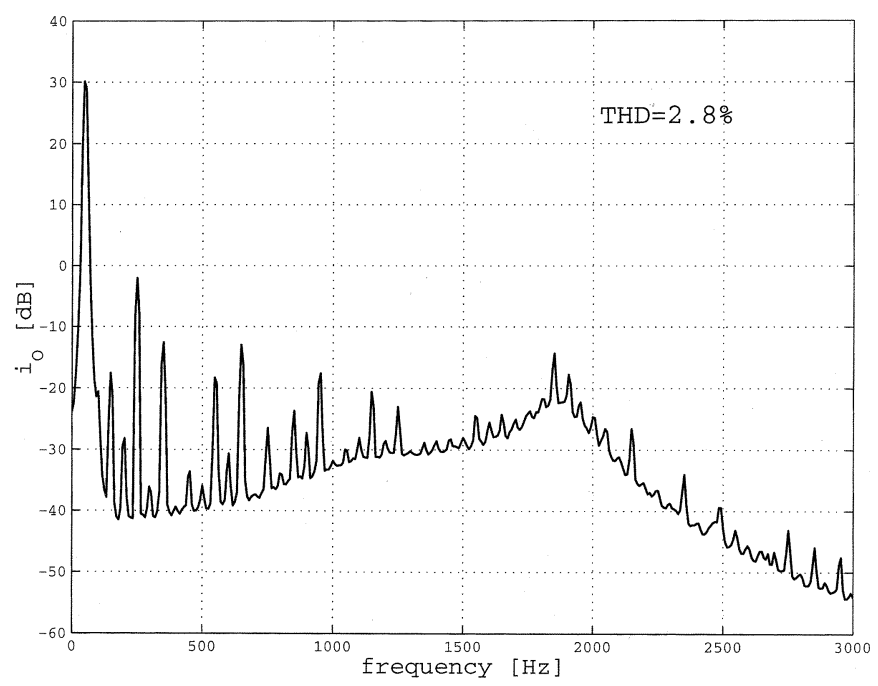

Fig. 17. Output current spectrum in controlled frequency range.

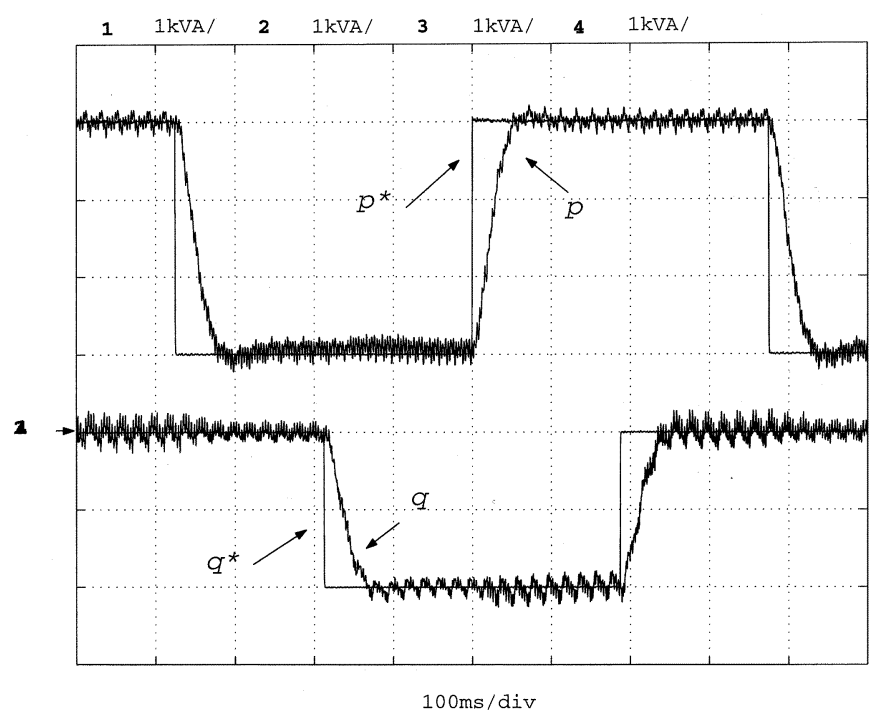

Fig. 18. Response of the real and reactive power loops to step changes in their respective reference values.

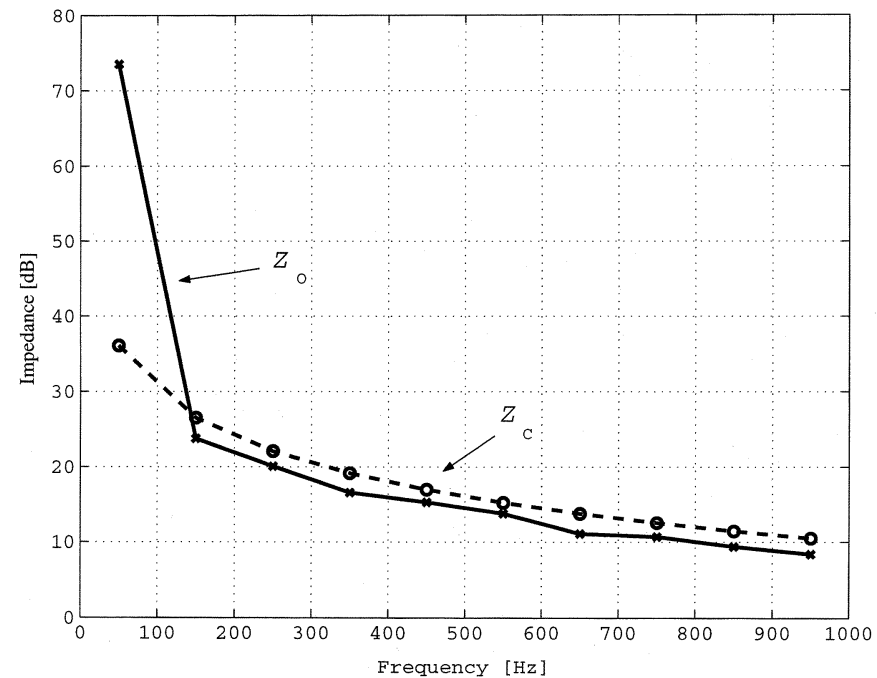

Fig. 19. Output impedance of the inverter and filter in closed loop compared to the impedance of the capacitor alone.

\section{CONCLUSION}

The integrated design of the filter and control strategy for a three-phase inverter has been investigated in order to provide high power quality when the inverter is connected to a grid as a power source. A full discrete-time controller design has been presented suitable for DSP implementation. The harmonic distortion requirements have been analyzed and two sources of distortion have been considered: the switching frequency components from the inverter and harmonic disturbance from the grid voltage.

The inverter filter design has been discussed in order to provide sufficient rejection of switching frequency components in the output current. Special attention has been paid to the fact that the inverter is connected to the grid via an isolating transformer. The properties of the transformer at harmonic frequencies have been used during the filter design.

Both voltage-mode and current-mode control have been examined in order to choose the appropriate control strategy for power quality. Both methods provide a solution for active and reactive power control but the current mode control has been chosen for its advantages in respect of rejection by the current control loop of harmonic distortion present in the grid. The benefits of controlling variables in the rotational reference frame instead of the stationary frame have been explained in respect of control structure requirements and power quality.

A control topology has been proposed involving three nested control loops: a phase-locked loop, an inductor current control-loop and an output power control-loop. Properties of the loops have been discussed, with emphasis on the current control loop and its structure. To minimize the effect of the sampling time delay, the operation of an estimator used has been examined. The controller and system decoupling structure have been explained.

The experimental results have shown that using the proposed design procedure, the switching frequency components can be satisfactorily attenuated. Results have been provided to substantiate both the power control and power quality. The power 
control results have shown stable and fast response to both active and reactive power demands. The power quality has been demonstrated with time and frequency domain results showing the high quality of the currents injected into the voltage grid.

\section{REFERENCES}

[1] M. H. Bollen, Understanding Power Quality Problems. Piscataway, NJ: IEEE Press, 2000

[2] IEEE CC21, IEEE P1547 Std Draft 06 Standard for Distributed Resources Interconnected With Electric Power Systems. Piscataway, NJ: IEEE, 2000.

[3] IEEE Industry Applications Society/Power Engineering Society, IEEE Recommended Practises and Requirements for Harmonic Control in Electrical Power Systems. Piscataway, NJ: IEEE, 1992.

[4] T. Kawabata, T. Miyashita, and Y. Yamamoto, "Dead beat control of three phase PWM inverter," IEEE Trans. Power Electron., vol. 5, pp. 21-28, Jan. 1990.

[5] Y. Ito and S. Kawauchi, "Microprocesor-based robust digital control for UPS with three-phase PWM inverter," IEEE Trans. Power Electron., vol. 10, pp. 196-204, Mar. 1995.

[6] J. D. Greene and C. A. Gross, "Nonlinear modeling of transformers," IEEE Trans. Ind. Applicat., vol. 24, pp. 434-438, May/June 1988.

[7] W. Dugui and X. Zheng, "Harmonic model of power transformer," in Proc. Power Syst. Technol. (POWERCON'98) Conf., vol. 2, Sept. 1998, pp. 1045-1049.

[8] N. Mohan, T. M. Undeland, and W. P. Robbins, Power Electronics. New York: Wiley, 1989.

[9] S. R. Bowes and B. M. Bird, "Novel approach to the analysis and synthesis of modulation processes in power convertors," Proc. Inst. Elect. Eng., vol. 122, pp. 507-513, May 1975.

[10] M. Chardokar, D. Divan, and R. Adapa, "Control of parallel connected inverters in stand-alone ac supply systems," IEEE Trans. Ind. Applicat., vol. 29, pp. 136-143, Jan./Feb. 1993.

[11] M. Yamaguchi, K. Kawarabayashi, and T. Takuma, "Development of a new utility-connected photovoltaic inverter LINE BACK," in Proc. 16th Int. Telecommun. Energy Conf. (INTELEC'94), Sept. 1994, pp. 676-682.

[12] E. Twining and D. Hohnes, "Grid current regulation of a three-phase voltage source inverter with an LCL input filter," in Proc. Power Electron. Spec. Conf., vol. 3, 2002, pp. 1189-1194.

[13] Q. Chongming and K. Smedley, "Grid current regulation of a three-phase voltage source inverter with an LCL input filter," in Proc. 36th IAS Annu. Meeting, Ind. Applicat. Conf., vol. 4, 2001, pp. 2675-2682.

[14] H. Akagi, Y. Kanazawa, and A. Nabae, "Instantaneous reactive power compensators comprising switching devices without energy storage components," IEEE Trans. Ind. Applicat., vol. IA-20, pp. 625-630, May/Jun. 1984
[15] P. Verdelho and G. D. Marques, "Four wire active power filter control circuit with phase locked loop phase angle determination," in Proc. 7th Int. Conf. Power Electron. Variable Speed Drives, 1998, 1998, pp. 34-39.

[16] N. Bruyant and M. Machmoum, "Simplified digital-analogical control for shunt active power filters under unbalanced conditions," in Proc. 7th Int. Conf. Power Electron. Variable Speed Drives, Sept. 1998, pp. 11-16.

[17] V. Kaura and V. Blasko, "Operation of a phase locked loop system under distorted utility conditions," in Proc. 11 th Annual Appl. Power Electron. Conf. Expo. (APEC'96), vol. 2, 1996, pp. 703-708.

[18] S.-K. Chung, "Phase-locked loop for grid-connected three-phase power conversion systems," IEEE Elec. Power Applicat., vol. 147, pp. 213-219, May 2000

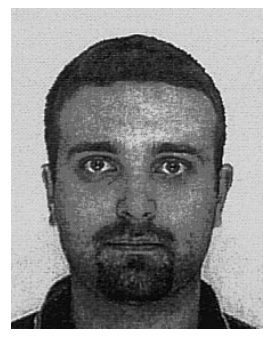

Milan Prodanović (S'01) received the B.Sc. degree in electrical engineering from the University of Belgrade, Yugoslavia, in 1996 and is currently pursuing the Ph.D. degree at Imperial College, London, UK.

From 1997 to 1999, he was engaged with GVS Engineering Company, Yugoslavia, developing power electronic circuits and control algorithms for inverter and UPS systems. His research interests are in digital control of power electronic systems, computeraided analysis and design of power converters, power quality, and distributed generation.

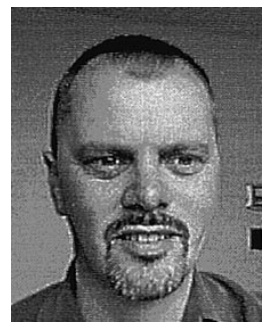

Timothy C. Green (M'89) received the B.Sc. degree (with first class honors) from Imperial College, London, UK, in 1986 and the Ph.D. degree from Heriot-Watt University, Edinburgh, UK, in 1990, all in electrical engineering.

He was at Heriot Watt University until 1994 and is now a Senior Lecturer at Imperial College and member of the Control and Power Research Group. He has research interests in power quality and power delivery covering distributed generation, micro-grids, active power filters, unified power flow controllers, and uninterruptible supplies. He also works on converter design and control for the implementation of FACTS.

Dr. Green is a Chartered Engineer in the UK. 